\title{
MiRNA-based therapeutic intervention of cancer
}

\author{
Srivatsava Naidu, Peter Magee and Michela Garofalo*
}

\begin{abstract}
MicroRNAs (miRNAs) are important modulators of eukaryotic gene expression. By targeting protein coding transcripts, miRNAs influence the cellular transcriptome and proteome, thus helping to determine cell fate. MiRNAs have emerged as crucial molecules in cancer research, in which recent studies have linked erratic expression of miRNAs to carcinogenesis and have provided solid evidence for their potential in cancer therapy. This review briefly summarises the recent knowledge on the involvement of miRNAs in tumourigenesis and reviews current studies on the therapeutic strategies and advances in the delivery of miRNAs.
\end{abstract}

Keywords: Noncoding RNAs, Cancer therapy

\section{Introduction}

MicroRNAs (miRNAs) are endogenous, small, noncoding RNAs that are highly conserved across various species of eukaryotes [1]. MiRNAs repress cellular translation and stability of a myriad of protein-coding transcripts by primarily targeting their 3' untranslated regions (UTRs) in a sequence-specific manner $[2,3]$. This selective silencing of gene expression by miRNAs has profound impact on human health and disease.

The latest release of miRBase [4] enlists at least 2588 miRNAs in humans. The canonical biogenesis of miRNAs is a tightly regulated process. Various epigenetic, transcriptional and processing mechanisms fine-tune the spatial and temporal expression of miRNAs [5]. MiRNA genes are predominantly transcribed by RNA polymerase II as primary miRNAs (pri-miRNAs) which are processed to precursor miRNAs (pre-miRNAs) in the nucleus by a microprocessor complex (composed of Drosha and DGCR8 (DiGeorge syndrome critical region 8)) [6]. Subsequently, pre-miRNAs are exported to the cytoplasm by Exportin-5-Ran-GTP complex [7], where Dicer1 cleaves the hairpin loop of premiRNA [8, 9] and TARBP2 (TAR RNA-binding protein 2) facilitates RNA duplex loading onto Argonaute protein AGO2 [10]. The antisense strand (mature) is retained by $\mathrm{AGO} 2$ and the sense strand is degraded, thus configuring a silencing complex [11] (Fig. 1). Non-canonical miRNA

\footnotetext{
* Correspondence: michela.garofalo@cruk.manchester.ac.uk Transcriptional Networks in Lung Cancer Group, Cancer Research UK Manchester Institute, University of Manchester, Wilmslow Road, Manchester M20 4BX, UK
}

biogenesis has also been reported, and these mechanisms are reviewed elsewhere [12].

MiRNAs silence gene expression via multiple mechanisms [13]. The current model suggests that miRISC (miRNA-induced silencing complex) binds to the complementary "seed" region within the 3' UTR of target mRNAs (messenger RNAs) and influences their degradation and/or the level of translation [3]. The thermodynamic stability of the miRNA-mRNA interaction is critical for effective repression of a potential target; however, other factors, including RNA secondary structure and spatial constraints posed by the same or other miRNA binding sites within the 3' UTR, may influence the silencing outcome of the target [14] (Fig. 1). Exponentially growing evidence confers the unique potential of miRNAs to modulate diverse biological processes, including cell growth and proliferation, cell cycle control, differentiation, apoptosis and tissue development $[15,16]$. Therefore, it is highly plausible that any aberration or deregulation in miRNA expression can be detrimental to the cell. Further, numerous studies have intimately linked erratic miRNA expression to the aetiology of cancer. Here, we briefly summarise the recent evidence for the involvement of miRNAs and miRNA-based therapeutic strategies in various cancers. Also, we highlight advances on the therapeutic delivery of miRNAs for the treatment of cancer.

\section{MiRNAs in cancer: a friend and foe}

The role of miRNAs in cancer was first reported by Calin et al. in chronic lymphocytic leukaemia [17]. Subsequently, 


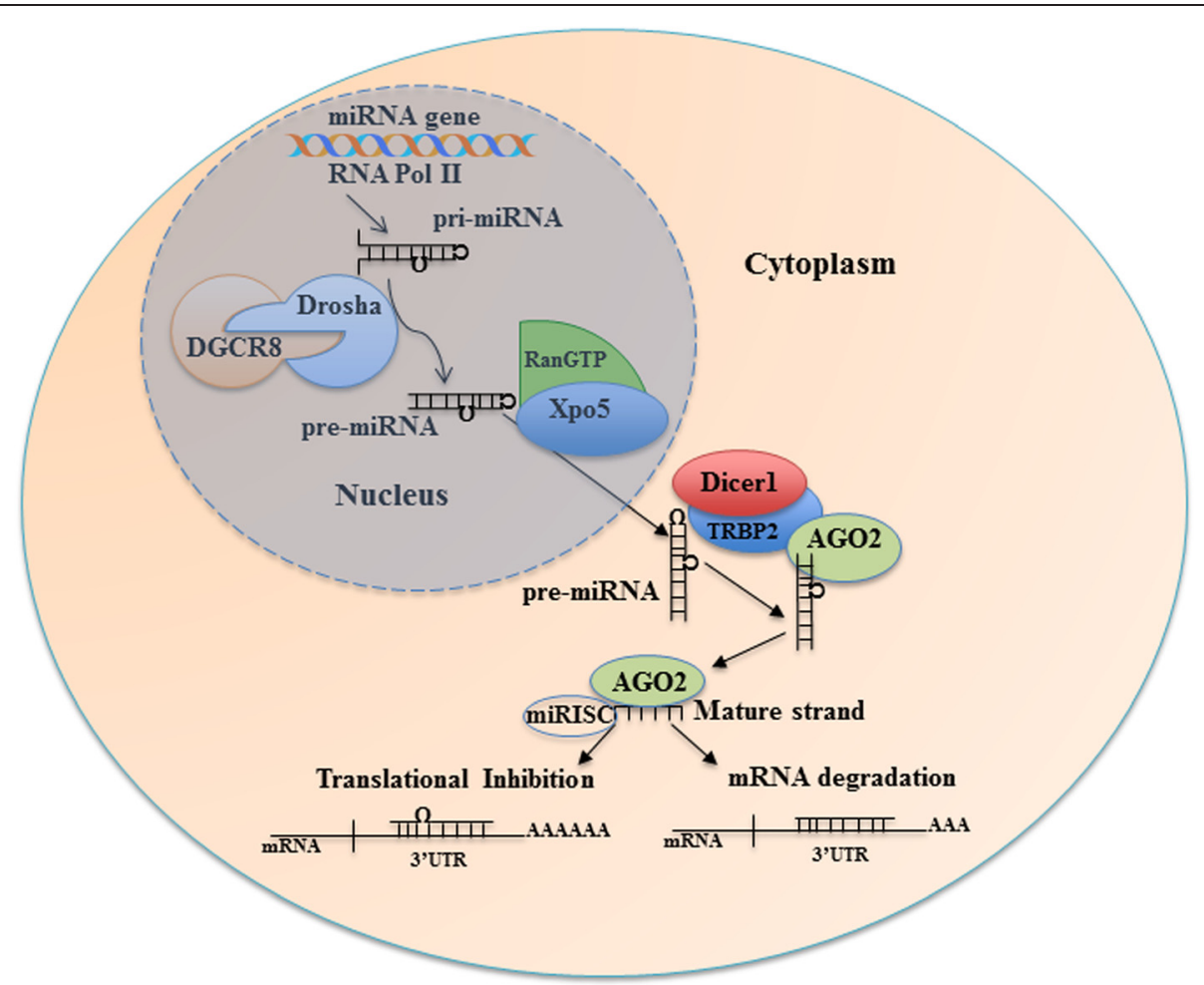

Fig. 1 The majority of miRNA genes are transcribed by the RNA polymerase II (Pol II) as primary miRNAs (pri-miRNAs) which are processed to precursor miRNAs (pre-miRNAs) via the Drosha-DGR8 complex. Pre-mRNAs are exported to the cytoplasm by Exportin-5-Ran-GTP (Xpo-5-RanGTP) where Dicer1 cleaves the hairpin loop and Tar RNA-binding protein 2 (TARBP2) facilitates the RNA duplex loading onto Argonaute protein AGO2. AGO2 and the mature strand enter a protein effector complex formed by the RNA-induced silencing complex (miRISC). The miRNA guides the RISC to messenger RNA targets causing either mRNA cleavage (perfect complementarity) or translational repression (imperfect complementarity)

a plethora of studies strongly correlated the deregulated expression of miRNAs in the hallmarks of cancer [18]. Diverse cellular mechanisms contribute to miRNA deregulation in cancer, and genetic changes [19], aberrant DNA methylation [20] and histone acetylation [21] have been attributed to miRNA deregulation. Importantly, cancerrelated transcription factors such as myc [22] and p53 [23] have been shown to influence miRNA expression. Additional mechanisms including alternative splicing, polyadenylation and mutations in miRNA processing machinery may also hamper miRNA maturation [24]. Aberrant loss or gain of miRNAs contributes to initiation, progression, metastasis and drug resistance of a wide spectrum of cancers. Depending on the genes and/or pathways they affect, miRNAs can act as tumour suppressors or oncogenes in a tissue-specific manner. For example, let-7 family miRNAs are known to be tumour suppressors. Downregulation of let-7 expression has been reported in head, neck, lung, breast, ovarian and prostate cancers [25]. Let-7 negatively regulates oncogenes such as KRAS, c-MYC, CDK6, HOXA9, TGFBR1, BCL-XL and MAP4K3, thereby promoting anti-oncogenic pathways [26]. Similarly, miR-34 family [27], miR-223 [28], miR-143/145 cluster $[29,30]$ and miR-204 [31] are commonly downregulated in various cancers; interestingly, reconstitution of respective miRNAs in these studies significantly reduced tumour growth. Interestingly, miR-214 is oncogenic in osteosarcoma [32] and nasopharyngeal cancer [33], whereas it appears to be a tumour suppressor in glioma [34] and colorectal cancer [35]. Similarly, miR-125b displays an oncogenic phenotype in colon and haematopoietic cancers, whereas it acts as a tumour suppressor in breast cancer and hepatocellular carcinoma [36]. Additional miRNAs, namely miR-17/92 cluster, miR-21, miR-155, miR-221, miR-222 and miR-9 are upregulated in various cancers [37]. Elevated miR-17/92 levels caused oncogenic activation of PI3K and NF-kB signalling in lymphomas [38]. MiR-21 overexpression has a causal role in tumourigenesis of pre-B cell lymphomas [39]. MiR-155 inhibition restored expression of tumour suppressor TP53INP1 and inhibited tumour development in breast cancer [40]. The intimate role of miRNAs in tumour metastasis, drug resistance and cancer stemness has been discussed elsewhere [41]. A more recent update on the role of miRNAs in various cancers has been tabulated (Table 1). Taken together, dysregulated miRNA expression appears to influence various hallmarks of cancer. A comprehensive understanding of miRNA biology in carcinogenesis can possibly pave novel routes for anti-cancer therapy. 
Table 1 A list of miRNAs involved in various cancer types. Corresponding functional role (phenotype) and validated targets (targets) are shown in separate columns

\begin{tabular}{|c|c|c|c|c|}
\hline Cancer & miRNA & Phenotype & Targets & Reference \\
\hline Lung cancer & miR-132/212 & TS & CyclinD1 & [72] \\
\hline \multirow[t]{7}{*}{ (NSCLC) } & miR-124 & TS & 5OX8 & {$[73]$} \\
\hline & miR-126 & TS & VEGF-PI3K-Akt-MRP1 & {$[74]$} \\
\hline & miR-181 & TS & $\mathrm{BCl} 2$ & {$[75]$} \\
\hline & miR-34a & TS & TGF $\beta R 2$ & {$[76]$} \\
\hline & miR-145 & TS & Oct-4 & {$[77]$} \\
\hline & miR-21 & OG & PDCD4 & {$[78]$} \\
\hline & miR-137 & PM & SLC22A18 & [79] \\
\hline \multicolumn{5}{|l|}{ Gastro-intestinal cancers } \\
\hline \multirow[t]{4}{*}{ Gastric cancer } & miR-335 & TS & RASA1 & {$[80]$} \\
\hline & miR-374b-5p & OG & RECK & [81] \\
\hline & miR-490-3p & OG & SMARCD1 & [82] \\
\hline & miR-199a-3p & OG & $\mathrm{ZHX} 1$ & [83] \\
\hline \multirow[t]{3}{*}{ Colorectal cancer } & miR-185 & TS-PM & STIM1 & [84] \\
\hline & miR-92a & OG-PM & PTEN & {$[85]$} \\
\hline & miR-7 & TS-PM & EGFR & {$[86]$} \\
\hline \multirow[t]{5}{*}{ Hepatocellular carcinoma } & miR-9 & PM & & {$[87]$} \\
\hline & miR-150-5p & TS & MMP14 & [88] \\
\hline & miR-21 & OG-PM & AP1 & [89] \\
\hline & miR-122 & TS & Hnf4a-GALNT10-EGFR & {$[90]$} \\
\hline & miR-486-5p & TS & PIK3R1 & [91] \\
\hline \multirow[t]{3}{*}{ Esophageal cancer } & miR-101, miR-127 & TS & MALAT1 & [92] \\
\hline & miR-126 & TS & DNMT1/ADAM9-EGFR & {$[93]$} \\
\hline & miR-27a & TS & K-Ras & [94] \\
\hline \multicolumn{5}{|l|}{ Haematological cancers } \\
\hline \multirow[t]{3}{*}{ Lymphoma } & miR-155-3p, & TS & LT- $\beta$ & {$[95]$} \\
\hline & miR-224 & TS-PM & CD59 & [96] \\
\hline & miR-17-92 & OG & Sin3b, Hbp1, Suv420h1, Btg1, Bim & [97] \\
\hline \multirow[t]{3}{*}{ Leukaemia } & miR-486-5p & OG & AKT-FOXO1 & {$[98]$} \\
\hline & miR-22 & OG & PTEN & [99] \\
\hline & miR-638 & TS & CDK2 & {$[100]$} \\
\hline \multicolumn{5}{|l|}{ Reproductive cancers } \\
\hline \multirow[t]{3}{*}{ Cervical cancer } & miR-126 & TS-PM & PTEN & [101] \\
\hline & miR-21, Let-7a & $\mathrm{OG} / \mathrm{TS}$ & STAT3 & [102] \\
\hline & miR-375 & DR & E-cadherin & [103] \\
\hline \multirow[t]{3}{*}{ Prostate cancer } & miR-3195, miR-374b & TS & HIF-1a, HIF-2a and VEGF & [104] \\
\hline & miR-218 & TS & TPD52 & [105] \\
\hline & miR-449b & PM & & [106] \\
\hline \multirow[t]{3}{*}{ Breast cancer } & miR-873 & TS-DR & $\mathrm{ERa}-\mathrm{CDK} 3$ & [107] \\
\hline & miR-18b, miR-103, miR-107 and miR-652 & PM & & [108] \\
\hline & miR-7 & TS-DR & EGFR, Src kinase & [109] \\
\hline
\end{tabular}


Table $1 \mathrm{~A}$ list of miRNAs involved in various cancer types. Corresponding functional role (phenotype) and validated targets (targets) are shown in separate columns (Continued)

\begin{tabular}{lllll}
\hline Glioblastoma & miR-125a-5p & TS & TAZ & [110] \\
& miR-155 & OG-DR & MAPK13 and MAPK14 & [111] \\
miR-449a & TS & MAZ & [112] \\
miR-148a & TS & Oct4, Sox-2 & [113] \\
\hline
\end{tabular}

Abbreviations: NSCLC non-small cell lung cancer; TS tumour suppressor; OG oncogenic; PM prognostic marker; DR drug resistance

\section{MiRNAs in cancer therapy: the potential}

MiRNAs are ubiquitously deregulated, as a cause or consequence, in virtually all cancers. By modulating multiple targets or entire pathways, and by having unique expression profiles and higher stability in biological samples, miRNAs have quickly gained diagnostic and therapeutic value. Modulating miRNA expression for cancer therapy is currently under investigation; in general, the therapeutic modulation of miRNAs is achieved by inhibiting oncogenic miRNAs, or by reconstituting tumour suppressor miRNAs. In recent years, the therapeutic potential of miRNAs in cancer has been demonstrated in several published studies (Table 1). For this review, we only focus on the most recent in vivo and preclinical studies which employed, either alone or in combination with conventional drugs, miRNAs as active agents against various cancers.

Xue et al. demonstrated that targeted delivery of miR$34 \mathrm{a}$ and K-ras siRNA into a murine lung cancer model resulted in significant tumour regression. Reconstitution of miR-34a reduced the mRNA levels of oncogenes such as Ccnd1, Sirt1, Cdk6 and Ccne2. Furthermore, modulating RNA delivery combined with cisplatin prolonged mice survival in this model [42]. In an independent study, combined reconstitution of miR-34 and let-7 reduced the expression of the tumour promoters Lin28b, c-Met and Myc and, as a consequence, tumour growth was drastically decreased in a murine model of nonsmall cell lung cancer (NSCLC) [43]. Another study reported that restoring miR-200c in a xenograft model enhanced sensitivity of lung tumours to radiation by targeting the expression of DNA repair protein RAD51 and oxidative stress response genes peroxiredoxin-2, Nrf2 and SESN1 [44]. Together, these in vivo models strongly support miRNAs as novel therapeutic options, either alone or in combination, for treating deadly lung cancers which are often presented with few treatment options.

Interestingly, two independent studies have demonstrated that targeted delivery of miR-520e [45] and miR375 [46] dramatically reduced liver cancer cell growth in in vivo xenograft models. Independently, ectopic expression of miR-217 significantly reduced tumour growth in a pancreatic ductal adenocarcinoma (PDAC) xenograft model [47]. Conversely, knockdown of oncogenic miR-21 expression combined with gemcitabine has been shown to be effective in controlling pancreatic ductal adenocarcinoma in a mouse model [48]. In addition, forced expression of miR-25 into a colon cancer mice model markedly reduced tumour burden [49]. Intriguingly, miR-182 expression promoted metastasis by modulating the expression of endothelial-mesenchymal transition (EMT) components in colorectal cancer; however, inhibition of miR-182 reversed this effect [50]. Taken together, these studies warrant the therapeutic benefits of miRNAs in the treatment of various gastro-intestinal cancers.

Liu et al. have shown that targeted downregulation of miR-106b-5p and its targets retinoblastoma-like 1 and 2 $(\mathrm{RBL} 1,2)$ and caspase- 8 inhibited glioma formation in a xenograft mice model [51]. Conversely, ectopic expression of miR-1 in glioblastoma-derived extracellular vesicles halted tumour growth, neovascularization and invasiveness [52]. Also, miR-142-3p overexpression modulated cytokine signalling in disease-associated infiltrating macrophages, resulting in glioma tumour growth inhibition [53]. These reports highlight the beneficial role of miRNAs in otherwise untreatable glioma.

Specific knockdown of miR-20b in a breast cancer nude mice model has shown to suppress tumour growth in vivo [54]. Intriguingly, a recent study demonstrated that in vivo delivery of miR-31 resulted in increased sensitivity for paclitaxel in an ovarian cancer model [55]. In the light of above studies, modulating miRNA expression appears to be a promising strategy for cancer therapy; however, caveats such as off-target effects, functional redundancy and dual nature (tumour promoter and tumour suppressor) should be considered carefully before utilising miRNAs for anti-cancer therapies.

\section{MiRNAs in cancer therapy: the challenge}

Successful translation of miRNAs into cancer therapeutics heavily depends on the specific, efficient and safe delivery of miRNA modulators to the tumour sites. Various biological barriers including in vivo nuclease degradation, fibrous nature of tumours, insufficiency of miRNA processing machinery and miRNA-induced immune response drastically hinder the bioavailability of ectopic miRNAs. Multiple approaches are in rapid development to circumvent these delivery hurdles. Chemical modifications on 2'-OH ribose [56] or phosphate backbone (locked nucleic acids, or LNAs) [57] made synthetic miRNAs less 
vulnerable to nuclease degradation, thus increasing in vivo stability and affinity to the target sequence. Various strategies have been developed for efficient delivery of miRNA modulators. Lentiviral, adenoviral and adeno-associated viral (AAVs) vectors expressing miRNA antagonists or mimics have proven to be effective delivery systems in various cancer models [58]. Importantly, cell-specific moieties can be engineered onto the viral capsid to enhance specificity uptake by cancer cells [59]. Non-integrating AAVs were successfully used as vehicles for miRNA replacement therapy in liver cancer [60]. Recently, exosomes and vesicles released by virus-infected cells have been shown to encapsulate and deliver miRNAs into the target cells, indicating that viral-derived exosomes can be exploited for miRNA delivery [61]. Another approach of vectors expressing tandem repeats of miRNA antisense sequences, termed miRNA sponges, can de-repress miRNA targets and have shown to be effective in modulating miRNA expression in vitro and in vivo [62], [63]. This approach offers a unique opportunity to target a family of miRNAs sharing the same seed sequence. A recent study engineered a vector expressing miRNA sponges and claims that this vector could circumvent some of the technical problems associated with this method [64]. Technological and engineering advancements have generated a variety of nanomaterials for miRNA delivery. Specifically, nanosized gold, carbon and silica particles have been used as carriers for miRNAs. Recently, systemic delivery of miR-34a-silica nanoparticles coated with tumour-specific antibody led to significant tumour growth inhibition and enhanced apoptosis in neuroblastoma [65]. Similarly, owing to their biodegradable property and high electrostatic affinity towards cellular membranes, cationic polymers have become an attractive option for miRNA transport. Poly-lacticco-glycolic acid (PLGA), polyethylenimine (PEI) and poly-dimethylaminoethyl methacrylate (PDMAEMA) are common cationic polymers used in nucleic acid delivery for cancer therapy. For example, systemic delivery of PLGA-based miR-21 and miR-10b antagonists in a breast cancer model caused dramatic effects on tumour regression [66]. Encouragingly, PEI-based miR-145 nanoparticles combined with radiation and chemotherapy significantly eliminated metastatic tumour nodules in a lung adenocarcinoma mice model [67]. Furthermore, Trang et al. successfully delivered lipid nanoparticles harbouring miR-34a or let-7 mimics which reduced tumour size in a K-ras-activated NSCLC mouse model [68]. Recently, advances in nanotechnology have led to an integrated diagnostic and therapeutic platform called "nanotheranostics" [69]. This novel system offers a unique possibility to load both diagnostic and therapeutic agents onto a single nanoparticle, thus facilitating to monitor the distribution, release and efficacy of drug in real time. Given the immense potential of miRNAs as biomarkers and therapeutic molecules, miRNA-based nanotheranostics could open novel avenues for personalised medicine in cancer therapy. Although current miRNA delivery methods (Table 2) have been promising in various experimental models, each of these systems suffers from various limitations. Despite the high transfection efficacy, viralbased delivery methods may elicit immune/inflammatory response, and may also suffer from the risk of integrating into the host genome, leading to oncogenic insertional mutagenesis. Nevertheless, advanced genetic engineering methods may lead to improved safety profiles for further exploiting these methods for therapeutic miRNA delivery. On the other hand, challenges such as cytotoxicity, nonspecific tissue distribution and high cost of production remains to be addressed for the nanoparticle-based delivery platforms. Therefore, a reliable, safe and cost-effective miRNA delivery strategy would largely be beneficial for exploiting miRNAs for clinical purposes.

\section{Future perspectives}

Given the heterogeneous nature of the disease and the limitations facing conventional therapies, cancer therapy needs to be multidimensional. Research so far has undoubtedly established the potential of miRNAs in diagnosis, therapy and prognosis of cancer. Successful in vivo and preclinical studies have appreciated the therapeutic potential of miRNAs for cancer treatment. For instance, restoring the expression of miRNAs such as Let 7, miR-16 and miR-31 has shown to have anti-cancer effects in various preclinical models [70]. Thus far, studies have proposed several miRNAs as potential candidates for cancer

Table 2 A summary of various miRNA delivery methods and their potential modulatory effects

\begin{tabular}{ll}
\hline Delivery method & Modulatory effect \\
\hline Viral based & Replacement/inhibition \\
Lentiviral & \\
Adenoviral & \\
Adeno-associated viral & Replacement/inhibition \\
Viral derived exosomes & \\
Nanoparticle based & \\
Inorganic & \\
Gold particles & \\
Carbon particles & \\
Silica particles & \\
Organic polymers & \\
Poly-lacticco-glycolic acid & \\
Polyethylenimine & \\
Poly-dimethylaminoethyl- methacrylate & \\
Lipid nanoparticles & Inhibition \\
\hline Sponges &
\end{tabular}


therapy [71]. In particular, miR-34, a key tumour suppressor miRNA, appears to be promising. Ectopic expression of miR-34 has shown to have therapeutic benefits for a variety of cancers [27]. Moreover, a liposome-based mimic of miR-34 (MRX34) developed by Mirna Therapeutics recently progressed into phase I clinical trials (identifier: NCT01829971). The outcome of this trial (due in December 2015) may hopefully provide more insights into this novel paradigm. Although technical challenges remain to be addressed, miRNA therapeutics appear to hold huge promise for cancer treatment, at least for those cancers where other treatment options have plateaued. Comprehensive understanding of the role of miRNAs in complex regulatory networks involved in cancer may help with designing combinatorial therapeutic strategies. Further developments in miRNA delivery technologies will hopefully translate miRNA-based cancer therapeutics into a clinical reality.

\section{Competing interests}

The authors declare that they have no competing interests.

\section{Authors' contributions}

SN drafted the manuscript and designed the figures. PM contributed to the figure design. MG conceived the study, participated in its design and coordination and helped to draft the manuscript. All authors read and approved the final manuscript.

Received: 10 March 2015 Accepted: 28 May 2015

Published online: 11 June 2015

\section{References}

1. Lagos-Quintana M, Rauhut R, Lendeckel W, Tuschl T. Identification of novel genes coding for small expressed RNAs. Science. 2001;294(5543):853-8. doi:10.1126/science.1064921.

2. Bartel DP. MicroRNAs: target recognition and regulatory functions. Cell. 2009;136(2):215-33. doi:10.1016/j.cell.2009.01.002.

3. Djuranovic $S$, Nahvi A, Green R. A parsimonious model for gene regulation by miRNAs. Science. 2011;331(6017):550-3. doi:10.1126/science.1191138.

4. Kozomara A, Griffiths-Jones S. miRBase: annotating high confidence microRNAs using deep sequencing data. Nucleic Acids Res. 2014;42(Database issue):D68-73. doi:10.1093/nar/gkt1181.

5. Davis BN, Hata A. Regulation of microRNA biogenesis: a miRiad of mechanisms. Cell Commun Signal CCS. 2009;7:18. doi:10.1186/1478-811×-7-18.

6. Han J, Lee Y, Yeom KH, Kim YK, Jin H, Kim VN. The Drosha-DGCR8 complex in primary microRNA processing. Genes Dev. 2004;18(24):3016-27. doi:10.1101/gad.1262504.

7. Bohnsack MT, Czaplinski K, Gorlich D. Exportin 5 is a RanGTP-dependent dsRNA-binding protein that mediates nuclear export of pre-miRNAs. RNA. 2004;10(2):185-91.

8. Hutvagner G, McLachlan J, Pasquinelli AE, Balint E, Tuschl T, Zamore PD. A cellular function for the RNA-interference enzyme Dicer in the maturation of the let-7 small temporal RNA. Science. 2001;293(5531):834-8. doi:10.1126/ science.1062961.

9. Ketting RF, Fischer SE, Bernstein E, Sijen T, Hannon GJ, Plasterk RH. Dicer functions in RNA interference and in synthesis of small RNA involved in developmental timing in C. elegans. Genes Dev. 2001;15(20):2654-9. doi:10.1101/gad.927801.

10. Chendrimada TP, Gregory Rl, Kumaraswamy E, Norman J, Cooch N, Nishikura K, et al. TRBP recruits the Dicer complex to Ago2 for microRNA processing and gene silencing. Nature. 2005;436(7051):740-4 doi:10.1038/nature03868.

11. Schwarz DS, Hutvagner G, Du T, Xu Z, Aronin N, Zamore PD. Asymmetry in the assembly of the RNAi enzyme complex. Cell. 2003;115(2):199-208.

12. Ha M, Kim VN. Regulation of microRNA biogenesis. Nat Rev Mol Cell Biol. 2014;15(8):509-24. doi:10.1038/nrm3838.
13. Valinezhad Orang A, Safaralizadeh R, Kazemzadeh-Bavili M. Mechanisms of miRNA-mediated gene regulation from common downregulation to mRNA-specific upregulation. Int J Genomics. 2014;2014:970607. doi:10.1155/2014/970607.

14. Fabian MR, Sonenberg $N$. The mechanics of miRNA-mediated gene silencing: a look under the hood of miRISC. Nat Struct Mol Biol. 2012;19(6):586-93. doi:10.1038/nsmb.2296.

15. Slaby O, Svoboda M, Michalek J, Vyzula R. MicroRNAs in colorectal cancer: translation of molecular biology into clinical application. Mol Cancer. 2009;8:102. doi:10.1186/1476-4598-8-102.

16. Small EM, Olson EN. Pervasive roles of microRNAs in cardiovascular biology. Nature. 2011;469(7330):336-42. doi:10.1038/nature09783.

17. Calin GA, Dumitru CD, Shimizu M, Bichi R, Zupo S, Noch E, et al. Frequent deletions and down-regulation of micro- RNA genes miR15 and miR16 at $13 q 14$ in chronic lymphocytic leukemia. Proc Natl Acad Sci U S A. 2002;99(24):15524-9. doi:10.1073/pnas.242606799.

18. Di Leva G, Garofalo M, Croce CM. MicroRNAs in cancer. Annu Rev Pathol. 2014;9:287-314. doi:10.1146/annurev-pathol-012513-104715.

19. Lagana A, Russo F, Sismeiro C, Giugno R, Pulvirenti A, Ferro A. Variability in the incidence of miRNAs and genes in fragile sites and the role of repeats and $\mathrm{CpG}$ islands in the distribution of genetic material. PLoS One. 2010;5(6):e11166. doi:10.1371/journal.pone.0011166.

20. Weber B, Stresemann C, Brueckner B, Lyko F. Methylation of human microRNA genes in normal and neoplastic cells. Cell Cycle. 2007;6(9):1001-5.

21. Saito Y, Liang G, Egger G, Friedman JM, Chuang JC, Coetzee GA, et al. Specific activation of microRNA-127 with downregulation of the protooncogene BCL6 by chromatin-modifying drugs in human cancer cells. Cancer Cell. 2006;9(6):435-43. doi:10.1016/j.ccr.2006.04.020.

22. Jackstadt R, Hermeking $H$. MicroRNAs as regulators and mediators of c-MYC function. Biochim Biophys Acta. 2014. doi:10.1016/j.bbagrm.2014.04.003.

23. Hunten $S$, Siemens $H$, Kaller M, Hermeking $H$. The p53/microRNA network in cancer: experimental and bioinformatics approaches. Adv Exp Med Biol. 2013;774:77-101. doi:10.1007/978-94-007-5590-1_5.

24. Jansson MD, Lund AH. MicroRNA and cancer. Molecular Oncol. 2012;6(6):590-610. doi:10.1016/j.molonc.2012.09.006.

25. Boyerinas B, Park SM, Hau A, Murmann AE, Peter ME. The role of let-7 in cell differentiation and cancer. Endocr Relat Cancer. 2010;17(1):F19-36. doi:10.1677/ERC-09-0184.

26. Wang X, Cao L, Wang Y, Wang X, Liu N, You Y. Regulation of let-7 and its target oncogenes (Review). Oncol Lett. 2012;3(5):955-60. doi:10.3892/ol.2012.609.

27. Misso G, Di Martino MT, De Rosa G, Farooqi AA, Lombardi A, Campani V, et al. Mir-34: a new weapon against cancer? Mol Therapy Nucleic Acids. 2014;3, e194. doi:10.1038/mtna.2014.47.

28. Haneklaus M, Gerlic M, O'Neill LA, Masters SL. miR-223: infection, inflammation and cancer. J Intern Med. 2013;274(3):215-26. doi:10.1111/joim.12099.

29. Akao Y, Nakagawa Y, Naoe T. MicroRNAs 143 and 145 are possible common onco-microRNAs in human cancers. Oncol Rep. 2006;16(4):845-50.

30. Takagi T, lio A, Nakagawa Y, Naoe T, Tanigawa N, Akao Y. Decreased expression of microRNA-143 and -145 in human gastric cancers. Oncology. 2009;77(1):12-21. doi:10.1159/000218166

31. Imam JS, Plyler JR, Bansal H, Prajapati S, Bansal S, Rebeles J, et al. Genomic loss of tumor suppressor miRNA-204 promotes cancer cell migration and invasion by activating AKT/mTOR/Rac1 signaling and actin reorganization. PLoS One. 2012;7(12):e52397. doi:10.1371/journal.pone.0052397.

32. Wang Z, Cai H, Lin L, Tang M, Cai H. Upregulated expression of microRNA-214 is linked to tumor progression and adverse prognosis in pediatric osteosarcoma. Pediatr Blood Cancer. 2014;61(2):206-10. doi:10.1002/pbc.24763.

33. Zhang ZC, Li YY, Wang HY, Fu S, Wang XP, Zeng MS, et al. Knockdown of miR-214 promotes apoptosis and inhibits cell proliferation in nasopharyngeal carcinoma. PLoS One. 2014;9(1):e86149. doi:10.1371/ journal.pone.0086149.

34. Wang S, Jiao B, Geng S, Ma S, Liang Z, Lu S. Combined aberrant expression of microRNA-214 and UBC9 is an independent unfavorable prognostic factor for patients with gliomas. Med Oncol. 2014;31(1):767. doi:10.1007/s12032-013-0767-5.

35. Chen DL, Wang ZQ, Zeng ZL, Wu WJ, Zhang DS, Luo HY, et al. Identification of microRNA-214 as a negative regulator of colorectal cancer liver metastasis by way of regulation of fibroblast growth factor receptor 1 expression. Hepatology. 2014;60(2):598-609. doi:10.1002/hep.27118.

36. Sun YM, Lin KY, Chen YQ. Diverse functions of miR-125 family in different cell contexts. J Hematol Oncol. 2013;6:6. doi:10.1186/1756-8722-6-6. 
37. Esquela-Kerscher A, Slack FJ. Oncomirs - microRNAs with a role in cancer Nat Rev Cancer. 2006;6(4):259-69. doi:10.1038/nrc1840.

38. Xiao C, Srinivasan L, Calado DP, Patterson HC, Zhang B, Wang J, et al. Lymphoproliferative disease and autoimmunity in mice with increased miR-17-92 expression in lymphocytes. Nat Immunol. 2008;9(4):405-14. doi:10.1038/ni1575.

39. Medina PP, Nolde M, Slack FJ. OncomiR addiction in an in vivo model of microRNA-21-induced pre-B-cell lymphoma. Nature. 2010;467(7311):86-90. doi:10.1038/nature09284.

40. Zhang CM, Zhao J, Deng HY. MiR-155 promotes proliferation of human breast cancer MCF-7 cells through targeting tumor protein 53-induced nuclear protein 1. J Biomed Sci. 2013;20:79. doi:10.1186/1423-0127-20-79.

41. Raza U, Zhang JD, Sahin O. MicroRNAs: master regulators of drug resistance, stemness, and metastasis. J Mol Med. 2014;92(4):321-36. doi:10.1007/s00109-014-1129-2.

42. Xue W, Dahlman JE, Tammela T, Khan OF, Sood S, Dave A, et al. Small RNA combination therapy for lung cancer. Proc Natl Acad Sci U S A. 2014;111(34):E3553-61. doi:10.1073/pnas.1412686111.

43. Kasinski AL, Kelnar K, Stahlhut C, Orellana E, Zhao J, Shimer E, et al. A combinatorial microRNA therapeutics approach to suppressing non-small cell lung cancer. Oncogene. 2014. doi:10.1038/onc.2014.282.

44. Cortez MA, Valdecanas D, Zhang X, Zhan Y, Bhardwaj V, Calin GA, et al. Therapeutic delivery of miR-200c enhances radiosensitivity in lung cancer. Mol Therapy J Am Soc Gene Therapy. 2014;22(8):1494-503. doi:10.1038/mt.2014.79.

45. Zhang S, Shan C, Kong G, Du Y, Ye L, Zhang X. MicroRNA-520e suppresses growth of hepatoma cells by targeting the NF-kappaB-inducing kinase (NIK). Oncogene. 2012;31(31):3607-20. doi:10.1038/onc.2011.523.

46. He XX, Chang Y, Meng FY, Wang MY, Xie QH, Tang F, et al. MicroRNA375 targets AEG-1 in hepatocellular carcinoma and suppresses liver cancer cell growth in vitro and in vivo. Oncogene. 2012;31(28):3357-69. doi:10.1038/onc.2011.500.

47. Zhao WG, Yu SN, Lu ZH, Ma YH, Gu YM, Chen J. The miR-217 microRNA functions as a potential tumor suppressor in pancreatic ductal adenocarcinoma by targeting KRAS. Carcinogenesis. 2010;31(10):1726-33. doi:10.1093/carcin/bgq160

48. Sicard F, Gayral M, Lulka H, Buscail L, Cordelier P. Targeting miR-21 for the therapy of pancreatic cancer. Molecul Therapy J Am Soc Gene Therapy. 2013;21(5):986-94. doi:10.1038/mt.2013.35.

49. Li Q, Zou C, Zou C, Han Z, Xiao H, Wei H, et al. MicroRNA-25 functions as a potential tumor suppressor in colon cancer by targeting Smad7. Cancer Lett. 2013;335(1):168-74. doi:10.1016/j.canlet.2013.02.029.

50. Yang MH, Yu J, Jiang DM, Li WL, Wang S, Ding YQ. MicroRNA-182 targets special AT-rich sequence-binding protein 2 to promote colorectal cancer proliferation and metastasis. J Transl Med. 2014;12:109. doi:10.1186/1479-5876-12-109

51. Liu F, Gong J, Huang W, Wang Z, Wang M, Yang J, et al. MicroRNA-106b-5p boosts glioma tumorigensis by targeting multiple tumor suppressor genes. Oncogene. 2014;33(40):4813-22. doi:10.1038/onc.2013.428.

52. Bronisz A, Wang Y, Nowicki MO, Peruzzi P, Ansari Kl, Ogawa D, et al. Extracellular vesicles modulate the glioblastoma microenvironment via a tumor suppression signaling network directed by miR-1. Cancer Res. 2014;74(3):738-50. doi:10.1158/0008-5472.CAN-13-2650.

53. Xu S, Wei J, Wang F, Kong LY, Ling XY, Nduom E et al. Effect of miR-142-3p on the M2 macrophage and therapeutic efficacy against murine glioblastoma. J Natl Cancer Inst. 2014;106(8). doi:10.1093/jnci/dju162

54. Zhou W, Shi G, Zhang Q, Wu Q, Li B, Zhang Z. MicroRNA-20b promotes cell growth of breast cancer cells partly via targeting phosphatase and tensin homologue (PTEN). Cell Biosci. 2014;4(1):62. doi:10.1186/2045-3701-4-62.

55. Mitamura T, Watari H, Wang L, Kanno H, Hassan MK, Miyazaki M, et al. Downregulation of miRNA-31 induces taxane resistance in ovarian cancer cells through increase of receptor tyrosine kinase MET. Oncogenesis. 2013;2, e40. doi:10.1038/oncsis.2013.3.

56. Davis $\mathrm{S}$, Lollo B, Freier $\mathrm{S}$, Esau C. Improved targeting of miRNA with antisense oligonucleotides. Nucleic Acids Res. 2006;34(8):2294-304. doi:10.1093/nar/gkl183.

57. Obad S, dos Santos CO, Petri A, Heidenblad M, Broom O, Ruse C, et al. Silencing of microRNA families by seed-targeting tiny LNAs. Nat Genet. 2011:43(4):371-8. doi:10.1038/ng.786.

58. Liu YP, Berkhout B. miRNA cassettes in viral vectors: problems and solutions. Biochim Biophys Acta. 2011;1809(11-12):732-45. doi:10.1016/ j.bbagrm.2011.05.014.
59. Sun $Y$, Yin G. Cell-specific delivery of messenger RNA and microRNA by recombinant MS2 virus-like particles carrying cell-penetrating peptide. Appl Microbiol Biotechnol. 2014. doi:10.1007/s00253-014-6274-6.

60. Kota J, Chivukula RR, O'Donnell KA, Wentzel EA, Montgomery CL, Hwang HW, et al. Therapeutic microRNA delivery suppresses tumorigenesis in a murine liver cancer model. Cell. 2009;137(6):1005-17. doi:10.1016/j.cell.2009.04.021

61. Pegtel DM, Cosmopoulos K, Thorley-Lawson DA, van Eijndhoven MA, Hopmans ES, Lindenberg $J$, et al. Functional delivery of viral miRNAs via exosomes. Proc Natl Acad Sci U S A. 2010;107(14):6328-33. doi:10.1073/pnas.0914843107.

62. Ebert MS, Sharp PA. MicroRNA sponges: progress and possibilities. RNA. 2010;16(11):2043-50. doi:10.1261/rna.2414110.

63. Li P, Sheng C, Huang L, Zhang H, Huang L, Cheng Z, et al. MiR-183/-96/-182 cluster is up-regulated in most breast cancers and increases cell proliferation and migration. Breast Cancer Res BCR. 2014;16(6):473. doi:10.1186/s13058-014-0473-z.

64. Cheng CJ, Bahal R, Babar IA, Pincus Z, Barrera F, Liu C, et al. MicroRNA silencing for cancer therapy targeted to the tumour microenvironment. Nature. 2015;518(7537):107-10. doi:10.1038/nature13905.

65. Tivnan A, Orr WS, Gubala V, Nooney R, Williams DE, McDonagh C, et al. Inhibition of neuroblastoma tumor growth by targeted delivery of microRNA-34a using anti-disialoganglioside GD2 coated nanoparticles. PLoS One. 2012;7(5):e38129. doi:10.1371/journal.pone.0038129.

66. Paulmurugan $\mathrm{R}$, Sekar NM, Sekar TV, editors. Biodegradable polymer nanocarriers for therapeutic antisense microRNA delivery in living animals, Proc. SPIE 8232, Colloidal Nanocrystals for Biomedical Applications VII, 823208 (2 February 2012). 2012. doi:10.1117/12.914830.

67. Chiou GY, Cherng JY, Hsu HS, Wang ML, Tsai CM, Lu KH, et al. Cationic polyurethanes-short branch PEl-mediated delivery of Mir145 inhibited epithelial-mesenchymal transdifferentiation and cancer stem-like properties and in lung adenocarcinoma. J Control Release Off Jo Control Release Soc. 2012;159(2):240-50. doi:10.1016/j.jconrel.2012.01.014.

68. Trang P, Wiggins JF, Daige CL, Cho C, Omotola M, Brown D, et al. Systemic delivery of tumor suppressor microRNA mimics using a neutral lipid emulsion inhibits lung tumors in mice. Mol Therapy J Am Soc Gene Therapy. 2011;19(6):1116-22. doi:10.1038/mt.2011.48.

69. Conde J, Edelman ER, Artzi N. Target-responsive DNA/RNA nanomaterials for microRNA sensing and inhibition: the jack-of-all-trades in cancer nanotheranostics? Adv Drug Deliv Rev. 2015;81C:169-83. doi:10.1016/ j.addr.2014.09.003

70. Kim M, Kasinski AL, Slack FJ. MicroRNA therapeutics in preclinical cancer models. Lancet Oncol. 2011;12(4):319-21. doi:10.1016/S14702045(11)70067-5.

71. Rothschild S. MicroRNA therapies in cancer. Mol Cell Therapies. 2014;2(1):7.

72. Luo J, Meng C, Tang Y, Zhang S, Wan M, Bi Y, et al. miR-132/212 cluster inhibits the growth of lung cancer xenografts in nude mice. Int J Clin Exp Med. 2014;7(11):4115-22

73. Xie C, Han Y, Liu Y, Han L, Liu J. miRNA-124 down-regulates SOX8 expression and suppresses cell proliferation in non-small cell lung cancer. Int J Clin Exp Pathol. 2014;7(11):7518-26.

74. Zhu X, Li H, Long L, Hui L, Chen H, Wang X, et al. miR-126 enhances the sensitivity of non-small cell lung cancer cells to anticancer agents by targeting vascular endothelial growth factor A. Acta Biochim Biophys Sin. 2012:44(6):519-26. doi:10.1093/abbs/gms026.

75. Huang $P$, Ye B, Yang Y, Shi J, Zhao H. MicroRNA-181 functions as a tumor suppressor in non-small cell lung cancer (NSCLC) by targeting $\mathrm{BCl}-2$. Tumour Biology: the journal of the International Society for Oncodevelopmental Biology and Medicine. 2014. doi:10.1007/s13277-014-2972-z.

76. Ma ZL, Hou PP, Li YL, Wang DT, Yuan TW, Wei JL, et al. MicroRNA-34a inhibits the proliferation and promotes the apoptosis of non-small cell lung cancer H1299 cell line by targeting TGFbetaR2. Tumour Biology: the journal of the International Society for Oncodevelopmental Biology and Medicine. 2014. doi:10.1007/s13277-014-2861-5.

77. Yin R, Zhang S, Wu Y, Fan X, Jiang F, Zhang Z, et al. MicroRNA-145 suppresses lung adenocarcinoma-initiating cell proliferation by targeting OCT4. Oncol Rep. 2011;25(6):1747-54. doi:10.3892/or.2011.1252.

78. Yang $Y$, Meng $H$, Peng Q, Yang X, Gan R, Zhao L, et al. Downregulation of microRNA-21 expression restrains non-small cell lung cancer cell proliferation and migration through upregulation of programmed cell death 4. Cancer Gene Ther. 2014. doi:10.1038/cgt.2014.66. 
79. Zhang B, Liu T, Wu T, Wang Z, Rao Z, Gao J. MicroRNA-137 functions as a tumor suppressor in human non-small cell lung cancer by targeting SLC22A18. Int J Biol Macromol. 2014;74C:111-8. doi:10.1016/j.j.jbiomac.2014.12.002.

80. Li Z, Li D, Zhang G, Xiong J, Jie Z, Cheng H, et al. Methylation-associated silencing of microRNA-335 contributes tumor cell invasion and migration by interacting with RASA1 in gastric cancer. Am J Cancer Res. 2014;4(6):648-62.

81. Xie J, Tan ZH, Tang X, Mo MS, Liu YP, Gan RL, et al. miR-374b-5p suppresses RECK expression and promotes gastric cancer cell invasion and metastasis. World J Gastroenterol WJG. 2014;20(46):17439-47. doi:10.3748/ wjg.v20.i46.17439.

82. Shen J, Xiao Z, Wu WK, Wang MH, To KF, Chen Y, et al. Epigenetic silencing of miR-490-3p reactivates the chromatin remodeler SMARCD1 to promote Helicobacter pylori-induced gastric carcinogenesis. Cancer Res. 2014 doi:10.1158/0008-5472.CAN-14-1301

83. Wang Z, Ma X, Cai Q, Wang X, Yu B, Cai Q, et al. MiR-199a-3p promotes gastric cancer progression by targeting ZHX1. FEBS Lett. 2014;588(23):4504-12. doi:10.1016/j.febslet.2014.09.047.

84. Zhang Z, Liu X, Feng B, Liu N, Wu Q, Han Y, et al. STIM1, a direct target of microRNA-185, promotes tumor metastasis and is associated with poor prognosis in colorectal cancer. Oncogene. 2014. doi:10.1038/onc.2014.404.

85. Ke TW, Wei PL, Yeh KT, Chen WT, Cheng YW. MiR-92a promotes cell metastasis of colorectal cancer through PTEN-mediated PI3K/AKT pathway. Ann Surg Oncol. 2014. doi:10.1245/s10434-014-4305-2.

86. Suto T, Yokobori T, Yajima R, Morita H, Fujii T, Yamaguchi S, et al. MicroRNA-7 expression in colorectal cancer is associated with poor prognosis and regulates cetuximab sensitivity via EGFR regulation. Carcinogenesis. 2014. doi:10.1093/ carcin/bgu242.

87. Cai L, Cai X. Up-regulation of miR-9 expression predicate advanced clinicopathological features and poor prognosis in patients with hepatocellular carcinoma. Diagn Pathol. 2014;9(1):1000. doi:10.1186/ s13000-014-0228-2.

88. Li T, Xie J, Shen C, Cheng D, Shi Y, Wu Z, et al. miR-150-5p inhibits hepatoma cell migration and invasion by targeting MMP14. PLoS One. 2014;9(12):e115577.

89. He X, Li J, Guo W, Liu W, Yu J, Song W et al. Targeting the microRNA-21/ AP1 axis by 5-fluorouracil and pirarubicin in human hepatocellular carcinoma. Oncotarget. 2014.

90. Wu Q, Liu HO, Liu YD, Liu WS, Pan D, Zhang WJ, et al. Decreased expression of hepatocyte nuclear factor 4alpha (Hnf4alpha)/microRNA-122 (miR-122) axis in hepatitis B virus-associated hepatocellular carcinoma enhances potential oncogenic GALNT10 protein activity. J Biol Chem. 2015;290(2):1170-85. doi:10.1074/jbc.M114.601203.

91. Huang X, Hou J, Shen X, Huang C, Zhang X, Xie Y, et al. MicroRNA-486-5p, which is downregulated in hepatocellular carcinoma, suppresses tumor growth by targeting PIK3R1. FEBS J. 2014. doi:10.1111/febs.13167.

92. Wang X, Li M, Wang Z, Han S, Tang X, Ge Y, et al. Silencing of long noncoding RNA MALAT1 by miR-101 and miR-217 inhibits proliferation, migration and invasion of esophageal squamous cell carcinoma cells. J Biol Chem. 2014. doi:10.1074/jbc.M114.596866.

93. Liu R, Gu J, Jiang P, Zheng Y, Liu X, Jiang X, et al. DNMT1-microRNA126 epigenetic circuit contributes to esophageal squamous cell carcinoma growth via ADAM9-EGFR-AKT signaling. Clinical Cancer Research: an official journal of the American Association for Cancer Research. 2014. doi:10.1158/ 1078-0432.CCR-14-1740.

94. Jiang Y, Duan Y, Zhou H. MicroRNA-27a directly targets to inhibit cell proliferation in esophageal squamous cell carcinoma. Oncol Lett. 2015:9(1):471-7. doi:10.3892/ol.2014.2701.

95. Yim RL, Wong KY, Kwong YL, Loong F, Leung CY, Chu R, et al. Methylation of miR-155-3p in mantle cell lymphoma and other non-Hodgkin's lymphomas. Oncotarget. 2014;5(20):9770-82.

96. Song G, Song G, Ni H, Gu L, Liu H, Chen B, et al. Deregulated expression of miR-224 and its target gene: CD59 predicts outcome of diffuse large B-cell lymphoma patients treated with R-CHOP. Curr Cancer Drug Targets. 2014;14(7):659-70

97. Li Y, Choi PS, Casey SC, Dill DL, Felsher DW. MYC through miR-17-92 suppresses specific target genes to maintain survival, autonomous proliferation, and a neoplastic state. Cancer Cell. 2014;26(2):262-72. doi:10.1016/ j.ccr.2014.06.014

98. Wang LS, Li L, Li L, Chu S, Shiang KD, Li M, et al. MicroRNA-486 regulates normal erythropoiesis and enhances growth and modulates drug response in CML progenitors. Blood. 2014. doi:10.1182/blood-2014-06-581926.
99. Palacios F, Prieto D, Abreu C, Ruiz S, Morande P, Fernandez-Calero T et al. Dissecting CLL microenvironment signals in unmutated patients: microRNA-22 regulates PTEN/AKT/FOXO pathway in proliferative leukemic cells. Leukemia \& lymphoma. 2014:1-15. doi:10.3109/10428194.2014.990900

100. Lin Y, Li D, Liang Q, Liu S, Zuo X, Li L, et al. miR-638 regulates differentiation and proliferation in leukemic cells by targeting cyclin-dependent kinase 2. J Biol Chem. 2014. doi:10.1074/jbc.M114.599191.

101. Yang Y, Song K, Chang H, Chen L. Decreased expression of microRNA-126 is associated with poor prognosis in patients with cervical cancer. Diagn Pathol. 2014;9(1):1001. doi:10.1186/s13000-014-0220-X.

102. Shishodia G, Verma G, Srivastava Y, Mehrotra R, Das BC, Bharti AC. Deregulation of microRNAs Let-7a and miR-21 mediate aberrant STAT3 signaling during human papillomavirus-induced cervical carcinogenesis: role of E6 oncoprotein. BMC Cancer. 2014;14(1):996. doi:10.1186/1471-2407-14-996.

103. Shen Y, Zhou J, Li Y, Ye F, Wan X, Lu W, et al. miR-375 mediated acquired chemo-resistance in cervical cancer by facilitating EMT. PLoS One. 2014;9(10):e109299. doi:10.1371/journal.pone.0109299.

104. Sohn EJ, Won G, Lee J, Lee S, Kim SH. Upregulation of miRNA3195 and miRNA374b mediates the anti-angiogenic properties of melatonin in hypoxic PC-3 prostate cancer cells. J Cancer Educ. 2015;6(1):19-28. doi:10.7150/jca.9591.

105. Han G, Fan M, Zhang X. MicroRNA-218 inhibits prostate cancer cell growth and promotes apoptosis by repressing TPD52 expression. Biochem Biophys Res Commun. 2015;456(3):804-9. doi:10.1016/j.bbrc.2014.12.026.

106. Mortensen MM, Hoyer S, Orntoft TF, Sorensen KD, Dyrskjot L, Borre M. High miR-449b expression in prostate cancer is associated with biochemical recurrence after radical prostatectomy. BMC Cancer. 2014;14:859. doi:10.1186/1471-2407-14-859.

107. Cui J, Bi M, Overstreet A, Yang Y, Li H, Leng Y, et al. MiR-873 regulates ERalpha transcriptional activity and tamoxifen resistance via targeting CDK3 in breast cancer cells. Oncogene. 2014. doi:10.1038/onc.2014.430.

108. Kleivi Sahlberg K, Bottai G, Naume B, Burwinkel B, Calin GA, Borresen-Dale A, et al. A serum microRNA signature predicts tumor relapse and survival in triple negative breast cancer patients. Clin Cancer Res: an official journal of the American Association for Cancer Research. 2014. doi:10.1158/10780432.CCR-14-2011.

109. Huynh FC, Jones FE. MicroRNA-7 inhibits multiple oncogenic pathways to suppress HER2Delta16 mediated breast tumorigenesis and reverse trastuzumab resistance. PLoS One. 2014;9(12):e114419. doi:10.1371/ journal.pone.0114419.

110. Yuan J, Xiao G, Peng G, Liu D, Wang Z, Liao Y, et al. MiRNA-125a-5p inhibits glioblastoma cell proliferation and promotes cell differentiation by targeting TAZ. Biochem Biophys Res Commun. 2014. doi:10.1016/j.bbrc.2014.12.078.

111. Liu Q, Zou R, Zhou R, Gong C, Wang Z, Cai T, et al. miR-155 regulates glioma cells invasion and chemosensitivity by p38 isforms in vitro. J Cell Biochem. 2014. doi:10.1002/jcb.25073.

112. Yao Y, Ma J, Xue Y, Wang P, Li Z, Li Z, et al. MiR-449a exerts tumorsuppressive functions in human glioblastoma by targeting Myc-associated zinc-finger protein. Mol Oncol. 2014. doi:10.1016/j.molonc.2014.11.003.

113. Lopez-Bertoni H, Lal B, Li A, Caplan M, Guerrero-Cazares H, Eberhart CG, et al. DNMT-dependent suppression of microRNA regulates the induction of GBM tumor-propagating phenotype by Oct4 and Sox2. Oncogene. 2014. doi:10.1038/onc.2014.334.

\section{Submit your next manuscript to BioMed Central and take full advantage of:}

- Convenient online submission

- Thorough peer review

- No space constraints or color figure charges

- Immediate publication on acceptance

- Inclusion in PubMed, CAS, Scopus and Google Scholar

- Research which is freely available for redistribution 